\title{
A TUTELA NORMATIVA DOS DIREITOS DA PERSONALIDADE FRENTE AOS AVANÇOS DA INTELIGÊNCIA ARTIFICIAL
}

\section{NORMATIVE GUARANTEE OF PERSONALITY RIGHTS BEFORE ADVANCES IN ARTIFICIAL INTELLIGENCE}

\author{
Matheus Ribeiro de Oliveira Wolowski * \\ Valéria Silva Galdino Cardin *1
}

\begin{abstract}
Resumo: O presente trabalho tem como objetivo compreender o contexto social da Inteligência Artificial e o Machine Learning e seus reflexos na sociedade contemporânea. Busca-se ainda, ponderar a necessidade de equilíbrio jurídico para atenuar eventuais efeitos negativos aos direitos da personalidade por meio de normas que direcionem o desenvolvimento sustentável da Inteligência Artificial. O método de pesquisa é o teórico, com análise de doutrinas e projetos de lei sobre o tema, partindo-se de premissas teóricas sobre o tema e extraindo conclusões que possam indicar possíveis caminhos para a resolução da problemática envolvendo o desenvolvimento da Inteligência Artificial e a proteção aos direitos da personalidade.
\end{abstract}

Palavras-chaves: Inteligência Artificial. Direitos da Personalidade. Políticas Públicas. Indústria 4.0. Ética.

Abstract: This work aims to understand the social context of Artificial Intelligence and Machine Learning and its reflexes in contemporary society. It also seeks to consider the need for legal balance to mitigate any negative effects to the rights of the personality through rules that guide the sustainable development of Artificial Intelligence. The research method is theoretical, with analysis of doctrines and bills on the theme, starting from theoretical premises on the theme and drawing conclusions that indicate possible ways to solve the problem involving, the development of Artificial Intelligence and the protection of personality rights.

\footnotetext{
* Doutorando em Direito pela Unicesumar - Bolsista PROSUP/CAPES; Mestre em Ciências Jurídicas Pela Unicesumar; Graduado em Direito e teologia pela Unicesumar; Professor universitário e advogado; E-mail: matheuswolowski@hotmail.com.

${ }^{11}$ Pós-Doutora em Direito pela Universidade de Lisboa; Doutora e mestre em Direito das Relações Sociais pela Pontifícia Universidade Católica de São Paulo (PUCSP); Docente da Universidade Estadual de Maringá e no Programa de Pós-graduação em Ciências Jurídicas pela Universidade CESUMAR; Pesquisadora pelo ICETI; Advogada no Paraná; E-mail: valeria@galdino.adv.br.
} 
Matheus Ribeiro de Oliveira Wolowski \& Valéria Silva Galdino Cardin

Keywords: Artificial intelligence. Personality Rights. Public policy. Industry 4.0. Ethic.

\section{INTRODUÇÃO}

A sociedade contemporânea tem presenciado o desenvolvimento tecnológico exponencial em diversos setores de produção e comunicação, tendo como marco o entendimento de que o momento atual se caracteriza pela indústria 4.0, cujo intuito consiste no desenvolvimento de tecnologias digitais.

Dentre as inúmeras tecnologias que se despontam no cenário hodierno, destacam-se as dotadas de Inteligência Artificial, pela eficiência e precisão na realização de tarefas complexas e a preocupação com eventuais efeitos negativos à sociedade, sobretudo à segurança de dados, a substituição da mão de obra humana e uso indevido para fins balísticos.

Ademais, enseja grande lacuna jurídica as eventuais consequências do avanço da Inteligência Artificial, uma vez que a máquina dotada de autonomia, pode tornar imprevisíveis as consequências e as tomadas de decisões e levar a discussão quanto à quem atribuir a responsabilidade civil, em caso de danos à terceiros.

O objetivo do presente trabalho consiste na pesquisa de conceitos gerais envolvendo a inteligência artificial de modo a compreender sua inserção na sociedade contemporânea, analisando alguns casos práticos de utilização da Inteligência Artificial no poder judiciário, nos transportes de veículos autônomos e outros setores da sociedade atual.

Por conseguinte, é importante se preocupar com os eventuais reflexos causados aos direitos de personalidade, aos direitos fundamentais e humanos, a fim de que a máquina não ultrapasse a soberania humana. Diante dessas problemáticas, faz-se necessário discutir caminhos para equilibrar o desenvolvimento das tecnologias de inteligência artificial, com os valores éticos e a mantença das proteções legais aos direitos de personalidade.

Utilizando-se do método hipotético-dedutivo, extraiu-se conceitos envolvendo a Inteligência Artificial e o Machine Learning, citando-se alguns casos práticos em que já é possível vislumbrar a Inteligência Artificial no cotidiano contemporâneo. Ademais, buscou-se avaliar diretrizes de atuação estatal sugeridas pela Comissão Europeia para a Inteligência Artificial, Estados Unidos e projetos de lei que tramitam no Brasil. 
Ao final, esperamos apontar os caminhos que norteiem normas legislativas globais a fim de que seja possível equilibrar o desenvolvimento da Inteligência Artificial com o respeito aos direitos fundamentais, humanos e de personalidade, de modo a assegurar a soberania humana e atenuar os possíveis problemas sociais que podem emergir na sociedade contemporânea.

\title{
1. INTELIGÊNCIA ARTIFICIAL NA INDÚSTRIA 4.0
}

As máquinas dotadas de inteligência artificial vêm tomando espaço no contexto atual, denominado de $4^{\mathrm{a}}$ revolução industrial ou indústria 4.0. Esse movimento foi protagonizado originariamente em 1956.

Esse contexto produtivo se caracteriza pela velocidade de desenvolvimento, segundo Damilano:

\begin{abstract}
A $4^{\mathrm{a}}$ Revolução Industrial (indústria 4.0) caracteriza-se pela eliminação de todas as fronteiras físicas, biológicas e digitais, se diferenciando das demais em razão da sua velocidade, profundidade e impacto sistêmico que a conduz. Um dos pilares da indústria 4.0 é a inteligência artificial (IA) que tem origem em 1956 quando John McCarthy utilizou o termo numa conferência de especialistas celebrada em Darmouth Colege. (DAMILANO, 2019, p.1986)
\end{abstract}

A Inteligência Artificial - IA ou AI (Artificial Intelligence) pode ser definida como - a capacidade de desenvolvimento de inteligência nos robôs, a qual alguns denominam racionalidade (RUSSELL; NORVIG, 2009, p.1152). Diversas ferramentas dotadas dessa tecnologia realizam atividades importantes que até então só eram possíveis de serem elaboradas por seres humanos, como, por exemplo: cirurgias, análise de exames médicos, elaboração de pareceres jurídicos e contratos, dentre outras atividades.

Veículos autônomos, também têm sido testados para facilitar o cotidiano dos seres humanos por empresas como a Tesla e a Uber. As ideias são inovadoras e atraem os olhares da sociedade nas fases embrionárias, entretanto o grande problema permeia quando surgem problemas de segurança, seja de dados ou até mesmo de danos patrimoniais.

O desenvolvimento da inteligência artificial tem sido cada vez mais intenso na sociedade contemporânea e as perspectivas para os próximos anos demonstram que os investimentos nestas tecnologias devem ser cada vez mais intensos.

A Comissão da União Europeia que trata acerca do tema, estima que serão majorados os volumes de investimento no setor de inteligência artificial, observe-se: “A Comissão está 
aumentando os investimentos em IA no âmbito do programa-quadro de pesquisa e inovação Horizonte 2020 para cerca de 1,5 bilhão de euros até o final de 2020 (isso equivale a uma média de 500 milhões de euros por ano e representa um aumento de cerca de 70\%)". (EUROPEAN COMISSION, 2018, p. 7)

Embora não se descarte essa possibilidade, a ciência não conseguiu até então desenvolver uma tecnologia de inteligência artificial completa, que seja completamente igual ao cérebro humano. Há possibilidades, até então, de que parcelas das habilidades humanas sejam realizadas por máquinas e não a totalidade de demandas que podem ser realizadas por um ser humano em virtude da sua ampla capacidade cognitiva.

É evidente que quando as máquinas se desenvolvem para uma finalidade específica ao ponto de realizá-las sem qualquer ingerência humana, o acabam fazendo com extrema perfeição e precisão, e, na grande maioria dos casos, melhor que os próprios seres humanos. O advento do Machine Learning (Aprendizado da máquina) é o que tem de mais avançado na inteligência artificial e tem sido utilizado nesses dispositivos que realizam tarefas específicas através da repetição.

Entende-se que,

\begin{abstract}
$\mathrm{O}$ aprendizado de máquina, em particular, é frequentemente descrito como o sofrimento da "maldição da dimensionalidade" (Domingos 2012). Em uma era de "big data", bilhões ou trilhões de exemplos de dados e milhares ou dezenas de milhares de propriedades dos dados (denominados "recursos" no aprendizado de máquina) podem ser analisados. A lógica de decisão interna do algoritmo é alterada à medida que 'aprende' nos dados de treinamento. - tradução nossa. (BURRELL, 2016, p.7)
\end{abstract}

Partindo dessa premissa, o Machine Learning pode ser definido como uma espécie de sistema de algoritmo, que permitem ao protótipo processar informações com forma de exemplos, sem necessidade de uma programação previamente definida, mas que se adapta com o tempo e com as experiências vivenciadas de forma interativa.

Ainda sobre tal conceito, tem-se que o Machine Learning,

\footnotetext{
são habilidades da inteligência artificial que permitem a um computador ajustar operações sem programação explícita na medida em que é exposto a novas informações, já o Deep Learning é uma das várias abordagens para o machine learning, e foi inspirado na estrutura e nas funções do cérebro humano, na interligação dos neurônios. (STAATS, 2020, p.4)
}

Inúmeros dispositivos de inteligência artificial possuem esse sistema e são capazes de participar de realizar diversas atividades que até então eram desenvolvidas apenas por seres 
humanos. Destaca-se que esse aprendizado ocorre de acordo com as experiências vivenciadas pela própria máquina, que aprimora suas habilidades ao longo do tempo de uso.

Nesta senda,

\begin{abstract}
A expansão das tecnologias, que viabilizam esses novos serviços de internet, leva a mudanças na maneira como as pessoas e as organizações interagem (LLOYD; FULLAGA; REID, 2016), dando origem a ambiguidades legais e problemas legais originais. Essas tecnologias incluem computação em nuvem, big data, Internet das Coisas (IoT), inteligência artificial (AI), criptografia, sensores, robôs, algoritmos e outros sistemas relacionados à informação. A maioria dessas tecnologias depende de infraestruturas de computação em nuvem para operar no nível superior. Um conceito específico conhecido como IoT é o principal facilitador para a conectividade de dispositivos de computação. A Internet das Coisas abraça um novo conceito pelo qual o mundo virtual da Internet converge com o mundo cotidiano das "coisas". A ideia é conectar pessoas entre si, mas também pessoas com organizações e itens do dia a dia. - tradução nossa - (SOARES; KAUFFMAN; CHAO; SAAD, 2020, p.3)
\end{abstract}

No âmbito do poder judiciário, a inteligência artificial já se encontra presente com inúmeros dispositivos capazes de elaborar contratos, petições iniciais, realizar pesquisas jurisprudenciais e avaliar casos que tenha o requisito de admissibilidade da Repercussão Geral nos Recursos Extraordinários submetidos ao Supremo Tribunal Federal brasileiro, no caso do Projeto Victor.

É importante considerar que,

O Projeto VICTOR consiste em um software de inteligência artificial para o reconhecimento, a partir de padrões alfanuméricos, da repercussão geral em recursos extraordinários, com funcionalidades que também incluem a separação e classificação de demandas, organização de temas pela análise de conteúdo e análise mais rápida dos processos. (ANDRADE; et al, 2019, p.4)

Portanto, não se tratam apenas de tecnologias automatizadas, mas de um arcabouço virtual capaz de substituir tarefas que até então eram designadas apenas aos seres humanos, o que gera uma enorme preocupação em relação as atividades profissionais, a segurança de dados, as questões éticas e demais perspectivas para o desenvolvimento futuro.

Estima-se que os níveis de integração da Indústria 4.0 e a troca de dados entre empresas levarão a extensas consequências organizacionais, resultando em riscos e oportunidades para os negócios de manufatura (BAUERNHANSL; HOMPEL; VO-GELHEUSER, 2014; BOTTHOF, 2015)

No mesmo sentido, Soares e Kauffman e Sales destacam que,

A sociedade contemporânea mundial passa por mudanças irreversíveis, cabendo ao sistema jurídico adequar-se a essa nova realidade. No direito brasileiro não é diferente, busca-se acompanhar as mudanças sociais, porém as discussões no âmbito jurídico com relação às inovações advindas da nova revolução industrial e o surgimento da Indústria 4.0 ainda não foram satisfatoriamente realizadas, pelo 

2019, p. 132)

Considerando a reflexão dos autores quanto ao momento embrionário em que se encontram as discussões jurídicas para acompanhar as mudanças sociais, emerge-se a preocupação em relação ao liame existente entre a Inteligência Artificial e os processos pedagógicos de ensino, bem como questões atreladas a responsabilidade civil e outros conflitos éticos.

\section{AS INQUIETAÇÕES GLOBAIS ANTE A EVENTUAIS VIOLAÇÕES ÉTICAS E DE DIREITOS FUNDAMENTAIS}

Seria possível, um software dotado de IA substituir um professor humano e ensinar os jovens e crianças no futuro? Essa reflexão também foi realizada pelo filósofo Vilém Flusser: “A escola não mais será lugar de ensino e de elaboração de dados. A escola alternativa será o lugar no qual inteligências artificiais serão programadas para que façam funcionar máquinas automatizadas" (FLUSSER, 2005, p. 6-7).

A afirmação de Flusser, embora especulativa, retrata uma preocupação social, sobretudo com a atividade docente e as variáveis decorrentes de eventuais problemas relacionados ao ensino de questões errôneas ou incapacidade de lidar com circunstâncias sociais mais sensíveis a capacidade humana de adaptação e percepção.

$\mathrm{Na}$ obra, Weapons of math destruction: how big data increases inequality and threatens democracy, Cathy O'Neil, realiza uma abordagem sobre o Projeto Impact, criado por Michelle Rhee e a empresa Mathematica Policy Research, cujo objetivo consiste na medição do progresso educacional através de cálculo de avanços e retrocessos durante o processo de aprendizagem de línguas e matemática para alunos regulares.

Entretanto, há ponderações que precisam ser observadas, veja-se:

Uma professora bem avaliada e com trabalho reconhecido por gestores, colegas, pais e alunos poderia ser demitida com base na pontuação do sistema estatístico de avaliação. O problema é apontado por O’Neil, que salienta a complexidade de avaliar o potencial de uma pessoa por meio de algoritmos. A variação no desempenho de um aluno de um ano para outro pode ocorrer por causa de vários fatores, como problemas familiares, financeiros, de relacionamento com colegas da escola ou de saúde, entre outros. (CAMPOS; LASTÓRIA, 2020, p.9) 
Portanto, o caso envolvendo o Projeto Impact demonstrou que, embora as máquinas possam realizar uma excelente apuração quantitativa, existem aspectos humanistas que ainda carecem da participação de professores qualificados para adaptarem a metodologia de ensino de acordo com as necessidades momentâneas que os seres humanos naturalmente carecem durante o período de desenvolvimento educacional.

A inteligência artificial pode se tornar uma importante ferramenta de auxílio no ensino e nessa realidade da indústria 4.0, fomentando a celeridade no processamento de dados e atenção e interação do estudante. Como assevera Flôres e Vicari, "Pela interação com outros assuntos, o uso da IA em ensino torna-se a melhor forma de transmissão de conhecimentos e, ainda, a motivação de novas pesquisas.” (FLÔRES; VICARI, 2005, p.12)

Contudo, os algoritmos não se mostram aptos à sensibilidade humana diante das controvérsias advindas de problemas familiares, financeiros, saúde ou até mesmo de formação básica de alguns estudantes que resultam em limitações de aprendizado de novos conteúdos. Portanto, a subjetividade de cada indivíduo deve ser levada em consideração, já que nem toda classe possui uma capacidade isonômica de aprender simultaneamente, dentro do mesmo espaço de tempo e sob a mesma linguagem, o referido conteúdo.

Acerca desse ponto,

\begin{abstract}
A educação seria impotente e ideológica se ignorasse o objetivo de adaptação e não preparasse os homens para se orientarem no mundo. Porém ela seria igualmente questionável se ficasse nisto, produzindo nada além de well adjusted people, pessoas bem ajustadas, em consequência do que situação existente se impõe precisamente no que tem de pior (ADORNO, 1995, p. 143).
\end{abstract}

Logo, no processo educacional deve-se considerar a necessidade de adaptação dos alunos diante de um mundo cada vez mais desafiador, sem deixar de resgatar a importância de compreensão do contexto social hodierno, com a presença de barbáries, injustiças e desigualdades, mesmo em meio aos avanços da tecnologia.

Joseph E. Aoun, e reitor da Northeastern University, defende, em seu livro Robotproof: higher education in the age of artificial intelligence, um sistema de ensino híbrido que consiga mesclar o desenvolvimento de habilidades que se demonstram capazes de acompanhar as mudanças tecnológicas, desenvolvendo-se ainda o pensamento crítico.

Sendo assim,

É essencial pensar nas possibilidades e contradições da hibridização entre o físico e o digital na educação, mas não para incentivar o uso tecnológico, e sim para preservar o que no ensino tradicional ainda pode atuar como impulsionador do 

sociedade. (CAMPOS; LASTÓRIA, 2020, p.16)

Inúmeros dispositivos de inteligência artificial possuem esse sistema e são capazes de participar de argumentações, construir jogadas de xadrez e até mesmo facilitar atividades de entretenimento no cotidiano, de acordo com as experiências vivenciadas.

No âmbito do poder judiciário, de forma incipiente, a inteligência artificial vem sendo introduzida para produzir pareceres jurídicos, para elaborar petições, para participar de debates e julgamentos, influenciando todo ambiente de trabalho judicial.

Deste modo,

a mesma maneira que a inteligência artificial e a automação exercem influência direta no meio ambiente de trabalho dos magistrados, também os advogados podem (e devem) contar com os computadores inteligentes para auxiliá-los em, pelo menos, alguma das etapas do atendimento jurídico (MARQUES, 2018, p. 53-54)

Grande parte das pesquisas indicam que a relação existente entre o Direito e a Inteligência Artificial surgiu em meados da década de 70 com a mudança de entendimento a fim de assegurar a aceitação da interdisciplinaridade existente entre a tecnologia e o Direito.

A relação do Direito com outras ciências é relativamente recente:

\begin{abstract}
IA e Direito consistem em produto tipicamente do século XX e XXI, não simplesmente em função dos avanços tecnológicos que tornaram possível falar em IA, mas também em razão do câmbio de paradigma na forma de encarar a integração interdisciplinar das ciências como um novo modelo teórico para responder a problemas que não são mais setorizados. Ainda que tivéssemos o avanço tecnológico suficiente para realizar esta integração, ou melhor, ainda que a IA fosse uma realidade, caso não houvéssemos tido este câmbio de ordem epistemológica, não havia sido possível conectar ciências tão distintas como o Direito e a Computação (MAGALHÃES, 2005,p. 361)
\end{abstract}

O Ross é o primeiro sistema alcunhado de "robô-advogado", que interage com o ser humano, apresentando respostas fundamentadas em frações de segundo após ser consultado (ROSS, 2018). Sistemas similares vêm emergindo ao longo do tempo. No Brasil, tem-se o robô advogado chamado de ELI, que foi criado pela empresa Tikal tech. Esse software é capaz de realizar cálculos e petições trabalhistas, cálculos de ICMS e inúmeros contratos em poucos minutos.

Evidentemente que tais avanços apresentam pontos positivos e também negativos. Dentre os pontos positivos, verifica-se a celeridade processual, uma vez que a inteligência artificial é capaz de processar uma imensa quantidade de dados e informações em frações de segundo, que demandariam muito mais tempo se realizado por um ser humano. Todavia, 
desperta-se a preocupação quanto aos eventuais danos que o avanço dessa tecnologia pode acarretar, como por exemplo, julgamentos incoerentes e violação aos direitos fundamentais.

O Conselho Nacional de Justiça informou que somente no ano de 2018, foram ajuizados 28,1 milhões de processos judiciais (CNJ, 2019, p. 219). Tal dado remete a magnitude de demandas ajuizadas no Estado brasileiro e, certamente, a estrutura do Poder Judiciário pode apresentar colapsos humanamente impossíveis de se resolver em um tempo satisfatório.

Nesse cenário, em 2018, o Supremo Tribunal Federal, passou a implementar um projeto de inteligência artificial, denominado de Victor, cuja função consiste em identificar quais recursos interpostos possuem repercussão geral, de acordo com as últimas decisões do tribunal, agilizando e facilitando a aplicação de precedentes. (BRASIL, 2018)

Neste sentido,

O Projeto VICTOR consiste em um software de inteligência artificial para o reconhecimento, a partir de padrões alfanuméricos, da repercussão geral em recursos extraordinários, com funcionalidades que também incluem a separação e classificação de demandas, organização de temas pela análise de conteúdo e análise mais rápida dos processos. (ANDRADE; et al, 2019, p.4)

O ministro Dias Toffoli, destacou que o sistema de inteligência artificial tem acuidade de $85 \%$, sendo,

\begin{abstract}
responsável pela identificação de processos de repercussão geral é um mecanismo que converte imagens em texto, o que melhora e dinamiza a avaliação dos processos. Segundo o ministro Dias Toffoli, além de poupar tempo para o trabalho da Justiça, a nova ferramenta pode economizar recursos humanos. "O trabalho que custaria ao servidor de um tribunal entre 40 minutos e uma hora para fazer, o software faz em cinco segundos. Nossa ideia é replicar junto aos Tribunais Regionais Federais (TRFs), aos Tribunais de Justiça, aos Tribunais Regionais do Trabalho, enfim, trata-se de uma ferramenta para toda a magistratura". (BRASIL, 2018).
\end{abstract}

Certamente o avanço tecnológico aparenta ser um caminho sem volta e o Projeto Victor é um exemplo disso, como embrião para a expansão em outros tribunais que compõe o Poder Judiciário. Embora a celeridade trazida pelo sistema de Inteligência Artificial seja interessante, a cautela que se deve ter consiste no problema de se antever a provável decisão do STF ao distribuir uma demanda.

Algumas pesquisas, por exemplo, já alertam para uma visão mais positivista da Inteligência Artificial,

A visão de Direito compartilhada por uma grande parcela dos investigadores da IA e Direito é eminentemente positivista, e que, por conseguinte, uma considerável parte 
dos sistemas construídos, até o momento, esteja baseada nesta perspectiva do Direito, ainda que diferentes correntes, como as que tentam formalizar o Direito tomando em conta o paradigma da argumentação jurídica (pós-positivismo), tentem escapar a esta visão positivista. (MAGALHÃES, 2005, p. 362)

Nessa perspectiva, os demandantes, com a ampliação natural do sistema, já poderiam compreender a sistemática objetiva do Victor ou outro sistema judiciário dotado de Inteligência Artificial e ter um parecer, sugerindo julgados aos juízes de primeira e segunda instância.

Em 21 de agosto de 2020, o Conselho Nacional de Justiça exarou a Resolução n. 332/2020, regulamentando, de forma embrionária, o uso da inteligência artificial no Poder Judiciário, a fim de que se assegure a transparência, ética e governança nesses processos.

$\mathrm{O}$ artigo $5^{\circ}$ dessa resolução, dispõe que, "a utilização de modelos de Inteligência Artificial deve buscar garantir a segurança jurídica e colaborar para que o Poder Judiciário respeite a igualdade de tratamento aos casos absolutamente iguais. "(BRASIL, 20202, p.4). Sabe-se, todavia, que mesmo alheia a intervenção da inteligência artificial, muitas decisões não garantem segurança jurídica, tampouco respeitam a igualdade de tratamento em casos semelhantes, gerando controvérsias no ambiente jurídico e acadêmico.

Possivelmente, com o advento da inteligência artificial, tais controvérsias tendem a diminuir, mas sempre haverá uma suspeição humana em relação a quem programa as referidas máquinas e que poderia, eventualmente, desrespeitar direitos fundamentais e até mesmo a segurança jurídica das decisões, principalmente diante de situações que resultem em problemas por “culpa da máquina”.

Tanto a empresa Uber quanto a Tesla sofreram questionamentos em relação a problemas que resultaram em óbito de pessoas durante testes de veículos autônomos, emergindo o questionamento acerca da possibilidade de se responsabilizar ou não a empresa fornecedora do produto, mesmo que o invento seja dotado de autonomia por conta da Inteligência Artificial, impedindo que o fornecedor possua previsibilidade das decisões tomadas pela máquina.

$\mathrm{O}$ aspecto ético que envolvem as pesquisas de maquinários dotados de Inteligência Artificial não se limita a relação do Direito com a IA assegurando à responsabilidade civil lugar de destaque nas polêmicas envolvendo a temática a fim de equilibrar os interesses da sociedade como possível vítima e dos investidores como possíveis responsáveis. 
Algumas linhas defendem a criação uma personalidade jurídica própria para IA, isto é, uma personalidade eletrônica. Recentemente, o Parlamento Europeu, fundado no art. 225 do Tratado sobre o Funcionamento da União Europeia, que autoriza solicitar à Comissão Europeia a redação de uma proposta legislativa, aprovou o Draft Report with Recommendations to the Comissionon Civil Law Rules on Robotics, de 31.5.2016.

Tal resolução propõe à Comissão sobre as Regras de Direito Civil em Robótica, em seu item 59, alínea "f”, que seja criado um status legal específico para robôs. (EUROPEAN PARLIAMENT, 2017). Sob essa premissa, defende-se na doutrina que,

\begin{abstract}
Nunca se exigiu, histórica e juridicamente, a presença de vida orgânica para que uma entidade tivesse atribuída a si personalidade, e, por decorrência, a capacidade de realizar atos jurídicos, como atesta o conhecido e solidamente estabelecido instituto da pessoa jurídica. Seria infundada, portanto, a negativa de conceder personalidade baseada em origem, visto que, há muito, o Direito permite personalidade a entes vazios de vida. (PIMENTEL JUNIOR, 2013, p. 17)
\end{abstract}

Essa seria uma teoria para aplicar a excludente de ilicitude do fornecedor, no sentido de que o problema ocorreu por um terceiro (já que se reconheceria a autonomia da IA).

Contudo, acredita-se que, ainda que estabelecida tal personalidade, no futuro, poderse-á aplicar o instituto da desconsideração da personalidade eletrônica, tal qual ocorre com pessoas jurídicas, o que dificulta a defesa dessa corrente. O uso da IA como ferramenta pressupõe a responsabilidade objetiva daquele que dela se utiliza ou em nome de quem ela é usada. (PIRES; SILVA, 2017).

Entretanto, a questão da responsabilidade ainda é uma incógnita no campo acadêmico, existindo diversos caminhos sem muita concretude, o que gera incertezas no presente e inseguranças para o futuro, uma vez que o Direito em geral, acaba não sendo tão célere quanto as mudanças advindas na sociedade, sobretudo no momento da Indústria 4.0.

\title{
3. DA NECESSIDADE DE UMA NORMA GLOBALIZADA PARA O DESENVOLVIMENTO RESPONSÁVEL DA INTELIGÊNCIA ARTIFICIAL FRENTE A PROTEÇÃO DOS DIREITOS DA PERSONALIDADE
}

O avanço das tecnologias no contexto econômico atual, suscita preocupação com eventual sucateamento do ser humano, principalmente nas relações de trabalho, com uma provável possibilidade de a máquina substituir a mão-de-obra humana.

Assim, o sociólogo Zygmunt Bauman, assevera que: 
O capitalismo é um sistema parasitário. Como todos os parasitas, pode prosperar durante certo período, desde que encontre um organismo ainda não explorado que lhe forneça alimento. Mas não pode fazer isso, sem prejudicar o hospedeiro, destruindo assim, cedo ou tarde, as condições de sua prosperidade ou mesmo de sua sobrevivência. (BAUMAN, 2010, p. 8-9)

Em grande parte das vezes, mesmo com diplomas internacionais e nacionais reconhecendo a proteção da dignidade da pessoa humana como valor máximo, na prática, não ocorre, tanto por parte do Estado, quanto por parte do indivíduo, isso por que o ser humano atual está cada vez mais egocêntrico, se olvidando do meio coletivo.

De qualquer forma, visando resolver esse impasse, tramita no Congresso Nacional o Projeto de Lei n. 5051 de 2019, de autoria do Senador Styvenson Valentim, com o objetivo de estabelecer princípios para o uso da Inteligência Artificial no Brasil. Em linhas gerais, o projeto busca implantar no Brasil, uma tendência mundial, de diretrizes para o avanço da Inteligência Artificial, traçando-se balizas a serem seguidas, conforme se observa:

\begin{abstract}
A disciplina do uso da Inteligência Artificial no Brasil tem como fundamento o reconhecimento de que se trata de tecnologia desenvolvida para servir as pessoas com a finalidade de melhorar o bem-estar humano em geral, bem como: I-o respeito à dignidade humana, à liberdade, à democracia e à igualdade; II-o respeito aos direitos humanos, à pluralidade e à diversidade; III-a garantia da proteção da privacidade e dos dados pessoais; IV-a transparência, a confiabilidade e a possibilidade de auditoria dos sistemas; V-a supervisão humana. (BRASIL, 2019, p.2)
\end{abstract}

Tal projeto de lei segue em tramitação do Parlamento brasileiro e aparenta ser influenciado com os que já vem sendo debatido ao redor do mundo para balizar o avanço responsável da Inteligência Artificial em todas as esferas, não apenas no Poder Judiciário, mas questões ligadas à proteção de direitos de personalidade dos usuários.

Dentre os pontos cardeais citados por Bonaldo e Cugini, destacam-se:

1) o princípio segundo o qual o controle humano deve ser necessário, sempre e em qualquer caso, uma vez que os sistemas de inteligência artificial devem ser concebidos como adequados para apoiar a autonomia humana e a tomada de decisões, de acordo com o princípio de respeito pela autonomia humana;

2) a robustez, confiabilidade e segurança inerentes a cada algoritmo, de modo a superar facilmente obstáculos, erros ou inconsistências que possam ter ocorrido durante a vida dos sistemas de inteligência artificial; (BONALDO; CUGINI, 2020, p.43)

Repisa-se que o debate acerca da inteligência artificial tem causado preocupação em diversas partes do mundo. Nuria Belloso Martin, pondera que tal preocupação que gerou inclusive a Declaração de Barcelona para o uso apropriada da inteligência artificial em 2017, 
bem como um manifesto informativo do instituto de inteligência artificial da Universidade de Nova York.

Martin pondera que,

\begin{abstract}
Existem preocupações sobre os usos que podem ser feitos da IA e a operação de algoritmos. Nesse sentido, houve várias iniciativas, criando grupos de pesquisa e estudo, como o B-Debate, sob proposta do Biocat e da Obra Social "la Caixa", que levaram à publicação da "Declaração de Barcelona para o uso adequado de Inteligência Artificial ", realizada em 8 de março de 2017. Este manifesto, aberto a novas assinaturas e comentários, levanta preocupações sobre o possível uso" inapropriado, prematuro ou malicioso "de novas tecnologias e, em troca, propõe um código de conduta baseado em seis pontos: prudência, confiabilidade, transparência, responsabilidade, autonomia restrita e papel humano. Também digno de nota é o relatório de 2017 do Instituto AI NOW da Universidade de Nova York 7, com recomendações importantes para o campo da inteligência artificial. - Tradução nossa - (MARTIN, 2019, p. 10)
\end{abstract}

A solução inicial para evitar os referidos problemas, consiste, portanto, na observância de seis pontos, quais sejam: prudência, confiabilidade, transparência, responsabilidade, autonomia limitada e o papel do ser humano. Tais condutas decorrem da preocupação com a eventual possibilidade de substituição do homem pela inteligência artificial, o que elevaria o número de desempregos e a desigualdade social.

O IA NOW ${ }^{2}$, instituto de inteligência artificial da Universidade de Nova York, elaborou um relatório ao final de 2018, exarando dentre inúmeras questões sobre o tema, dez recomendações prioritárias, a fim de prevenir prejuízos e danos causados na sociedade, nela incluída, o poder judiciário.

As recomendações consistem, sobretudo, em transparência, regulação e segurança, destacando-se que:

Os governos precisam regular a IA expandindo os poderes das agências específicas do setor para supervisionar, auditar e monitorar essas tecnologias por domínio; O reconhecimento facial e o reconhecimento de afetação precisam de regulamentação rigorosa para proteger o interesse público; É necessário mais financiamento e apoio para litígios, organização do trabalho e comunidade participação em questões de responsabilidade da IA; Os programas de IA da universidade devem se expandir para além da ciência e engenharia da computação disciplinas. (WHITTAKER, 2018)

Verifica-se que as recomendações residem no âmbito da transparência e reponsabilidade social, a fim de se resguardar dos direitos de personalidade e demais direitos

2 Fundado em 2017 por Kate Crawford e Meredith Whittaker, o AI Now está localizado na New York University, onde promove um envolvimento intelectual por meio de colaborações em uma rede expansiva de classe mundial que inclui acadêmicos, tecnólogos, políticos, juristas e muitos outros profissionais. O AI Now Institute produz pesquisas interdisciplinares sobre as implicações sociais da inteligência artificial e atua como um centro para o campo emergente focado em quatro domínios principais: direitos e liberdades, trabalho e automação, preconceito e inclusão e segurança e infraestrutura crítica. 
sociais como o trabalho. Os desafios na inteligência artificial são imensos não só para solucionar os problemas atuais, mas para evitar que outros problemas surjam no presente e futuro, incluindo-se, sobretudo o julgamento com equidade através de dispositivos dotados de inteligência artificial.

A UNI Global ${ }^{3}$, estabeleceu dez princípios éticos para a Inteligência Artificial, para nortear a relação entre trabalhadores, administradores de loja e Estados, garantindo os direitos e a influência dos trabalhadores na idade da digitalização. Dentre pressupostos estabelecidos, destacam-se a transparência do sistema, a necessidade de governança global e a proibição de responsabilidade aos robôs. (UNI GLOBAL UNION)

Resta evidente que a máquina poderá, por intermédio da Inteligência Artificial apresentar não só caminhos para uma análise superior à análise humana em casos judicantes, como também em intervenções médicas, diagnósticos de doenças e solução de outras problemáticas existentes.

Evidentemente, tal qual sinalizam os pesquisadores em países europeus, Estados Unidos e Brasil, a cautela deve ser a máxima, não permitindo que a Inteligência Artificial permaneça desacompanhada da transparência e supervisão humana, principalmente na questão envolvendo o julgamento, tarefa essa que compete ao ser humano, que poderá se utilizar da Inteligência Artificial.

Sendo assim,

Apesar de todos os avanços tecnológicos, considerando as especialidades dos recursos linguísticos, de natureza ontológica ou semântica, somadas à peculiaridade dos serviços jurisdicionais e à integridade das relações sociais, conclui-se que essas tecnologias, por mais desenvolvidas que sejam, não se posicionam acima dos magistrados, mas ao seu lado, como ferramentas para apoiar a prática jurisdicional. O íntimo científico deve definitivamente permanecer sob o domínio humano, o único capaz de transformar o texto por contexto em norma jurídica capaz de garantir, a qualquer momento, a efetividade da Justiça no meio de uma sociedade tão dinâmica e transformadora como é hoje. (DO CARMO; GERMINARI; GALINDO, 2019, p.246)

\footnotetext{
${ }^{3}$ UNI Global Union foi fundada como Union Network International em 2000 e reuniu quatro organizações sindicais globais: FIET (Federação Internacional de Funcionários, Técnicos e Gerentes), MEI (Mídia e Entretenimento Internacional), IGF (Federação Gráfica Internacional e CI (Communications International .) A instituição tem como objetivo, apoiar trabalhadores nos setores de serviços em todo o mundo por meio do crescimento dos sindicatos e da expansão da negociação coletiva; melhorar as condições de trabalho e de vida dos trabalhadores; e apoiar empregos decentes para todos e crescimento econômico sustentável. Dentre as preocupações da organização, está a necessidade de equilibrar o avanço da Inteligência Artificial no mundo globalizado e atenuar os efeitos do desemprego e violações aos direitos humanos de trabalhadores que poderão ser substituídos pelas máquinas.
} 
Ademais, aliar a inteligência artificial com o raciocínio humano, pode trazer resultados satisfatórios. No caso da problemática do Judicial Review, sob a análise da repercussão geral, desenvolver uma inteligência artificial que reúna o número de processos ajuizados no país com temática semelhante, destacando-se ainda a quantidade de decisões divergentes sobre a mesma temática (como já faz o Victor) e, submetendo ao crivo de instituições representativas como a Ordem dos Advogados do Brasil, Congresso Nacional, Associações de Magistrados, Conselho Nacional de Justiça e outros para convalidação do aspecto de repercussão geral, podendo ainda, ser apreciado conjuntamente por tais órgãos, legislações incipientes que sequer foram objeto de litígio, mas que geram enormes controvérsias e riscos de insegurança jurídica, medidas emergenciais para atenuar as consequências econômicas causadas pelo COVID-19.

No tocante a relação com os direitos de personalidade, importante se observar as diretrizes dos países europeus e também defendidas nos Estados Unidos, resguardando a transparência e auditorias em dispositivos que envolvam Inteligência Artificial, observando-se os impactos sociais a fim de propor mecanismos para atuar os efeitos da expansão da Inteligência Artificial no ambiente de trabalho, no trato com a privacidade dos seres humanos e na segurança quanto ao armazenamento das informações personalíssimas.

Diante dessas circunstâncias, sugere-se a proteção legal de se incentivar o uso da Inteligência Artificial no ensino, mas sempre com a supervisão de um docente capacitado, a fim de que o aluno consiga absorver as competências necessárias para a realidade tecnológica, mas sempre acompanhado de reflexões críticas e criativas do professor, que também poderá visualizar eventuais causas de descompassos de aprendizagem, diante das variáveis humanas que permeiam a falibilidade e a vulnerabilidade humana.

Essa supervisão humana, assegurada em lei, afastaria a problemática da responsabilidade civil no caso de conclusões errôneas exaradas por equipamentos de inteligência artificial, já que no caso de falhas, o ser humano supervisor, prontamente, corrigiria aos alunos a informação, bem como a própria máquina em processo de constante aprendizagem (Machine Learning).

Acerca do tema, Barfield pondera que alguns autores defendem que a responsabilidade da máquina seria semelhante à imputada ao animal atualmente, já que ela, em muitos casos, reage e age de forma imprevisível e independente. Todavia, o autor não concorda com essa 
responsabilização, defendendo a criação de uma personalidade própria aos sistemas inteligentes a fim responsabilizá-los por seus atos.

Observe-se:

\begin{abstract}
Além disso, casos de responsabilidade estrita não impõem responsabilidade ao fabricante e a outras partes da cadeia de distribuição pelas alterações feitas no produto após a entrega ao consumidor, a menos que essas alterações sejam previsíveis. Como os robôs autônomos podem "mudar" de sua programação original, suas ações podem não ser previsíveis. A previsibilidade torna a responsabilidade do estado inadequada para lesões causadas por robôs autônomos (BARFIELD, 2018, p. 198).
\end{abstract}

A imputação de responsabilidade à própria máquina, defendida por Barfield é questão de elevada polêmica, já que essa, possivelmente não teria plenas condições de adimplir com uma indenização civil, ou cumprir alguma pena "restritiva de direitos" no espectro criminal. Portanto, no processo educacional, se apresenta como mais adequada a presença de um docente humano, supervisionando a utilização da IA e, em casos de danos graves aos alunos, esse poderá ser responsabilizado de forma solidária com os fabricantes da máquina.

Ademais, a presença do professor humano pode minimizar outros dois problemas: o distanciamento da realidade humana no contexto social e um eventual afeto pela máquina que podem resultar em danos à incolumidade psíquica do ser humano e a consequente ofensa aos direitos de personalidade.

Ao longo da jornada escolar ou acadêmica, é natural que o ser humano desenvolva admiração por parte do corpo docente e busque inspiração para sua carreira profissional. Mais do que repassar um conteúdo, o professor possui um papel importante em sala de aula como agente de transformação social e referência para os alunos. Portanto, para preservar a soberania humana, é importante que a legislação assegure a presença do professor em sala de aula, a fim de mantes as raízes antropológicas do relacionamento social.

Já defendia Aristóteles que "que o homem por natureza é um animal político [isto é, destinado a viver em sociedade], e que o homem que, por sua natureza e não por mero acidente, não tivesse sua existência na cidade, seria um ser vil”. (ARISTÓTELES, 2009, p. 56). Dessa forma, é importante preservar a essência humana do convívio social, sobretudo no processo educacional, ainda que se introduza a Inteligência Artificial em sala de aula.

Essa questão, certamente preservaria a dignidade e soberania humana. Como afirma Immanuel Kant,

No reino dos fins tudo tem ou um preço ou uma dignidade. Quando uma coisa tem um preço, pode ser substituída por algo equivalente; por outro lado, a coisa que se 
acha acima de todo preço, e por isso não admite qualquer equivalência, compreende uma dignidade. (KANT, 2002, p. 65)

Logo, há uma similitude entre a dignidade e a soberania humana, e, por mais relevante e instigante que seja o avanço tecnológico, o ordenamento jurídico deve preservar a soberania humana e, neste caso, a dignidade do professor. Até por que a inteligência artificial não é capaz de reproduzir a inteligência humana em sua totalidade, ante a complexidade das atividades cerebrais. Contudo, deve ser utilizada como uma ferramenta de auxílio no processo educacional, mas sempre com a supervisão e complementação do professor humano, que não fará mais o trabalho mecânico, mas desenvolverá o raciocínio crítico e humanizado em sala de aula, preparando os estudantes para o mercado de trabalho e o convívio social.

O sistema constitucional brasileiro exige a proteção do Estado quanto aos direitos humanos $\mathrm{e}$ fundamentais sobre os novos fenômenos sociais que emergem na contemporaneidade, dentre eles o avanço da tecnologia e da inteligência artificial. Portanto, o Estado tem a obrigação jurídica de fazer o possível para proteger os Direitos Fundamentais como bens jurídicos que devem ser preservados contra violações e ameaças antijurídicas. (HESSE, 1998, p. 278), através de legislações globais eficientes, alinhadas entre si e que assegurem o avanço tecnológico responsável, sempre em respeito à proteção aos direitos fundamentais e de personalidade, bem como os demais reflexos jurídicos dessa nova realidade social.

Neste sentido, a Unesco, em 15 de maio de 2020 elaborou um esboço de recomendações éticas para o desenvolvimento da inteligência artificial, das quais se destacam a preocupação de uma legislação internacional padronizada, observe-se:

\footnotetext{
Os governos devem desempenhar um papel de liderança na garantia da segurança e proteção dos sistemas de IA, inclusive estabelecendo padrões nacionais e internacionais consistentes com as leis, padrões e princípios internacionais aplicáveis de direitos humanos. A pesquisa estratégica sobre os riscos potenciais de segurança e proteção associados a diferentes abordagens para tornar a IA eficaz a longo prazo deve ser constantemente apoiada para evitar danos catastróficos. Tradução nossa - (UNESCO, 2020, p. 11)
}

Isso se torna necessário, uma vez que a economia é totalmente globalizada e o compartilhamento de tecnologia é natural nos dias modernos. Logo, as normas que devem regulamentar o avanço da inteligência artificial também precisam ser globais para que inexista qualquer desrespeito aos direitos humanos ou até mesmo o uso indiscriminado para finalidades bélicas. 
Embora não se tenha total garantia de que essa recomendação seja acolhida pela grande maioria dos países, resta evidente que, para se assegurar o desenvolvimento equilibrado da inteligência artificial, rompendo com eventuais dúvidas de seu funcionamento e eventuais violações aos direitos fundamentais ou até mesmo da soberania humana, tal alinhamento legislativo se torna de grande relevância para o equilíbrio e segurança no futuro.

\section{CONCLUSÕES}

Cada vez mais os avanços tecnológicos emergem na sociedade e certamente não há razões para detê-los, uma vez que, em geral, trazem benefícios positivos para os seres humanos, com a precisão em tarefas complexas, celeridade e eficiência que não se encontram nas capacidades humanas em geral.

No sistema judiciário brasileiro, por exemplo, observou-se que há grandes avanços com a implantação do Projeto Victor, reduzindo à segundos, tarefas que eram realizadas por quase uma hora, resultando em celeridade nos processos judiciais. Veículos autônomos também emergem como alternativa para o transporte de seres humanos e o ensino já pode ter como aliado a Inteligência Artificial.

Entretanto, nada é absolutamente perfeito e, por mais que hajam inúmeras razões benéficas nas tecnologias, encontram-se também desafios que necessitam de maiores reflexões para evitar violação à direitos fundamentais e de personalidade.

Majoritariamente, os direitos fundamentais buscam ser efetivados através de políticas públicas eficientes que preveem o equilíbrio de interesses financeiros e sociais, consolidando a soberania humana, com a tutela da dignidade humana e até mesmo a saúde financeira do Estado que, geralmente custeia essas políticas públicas.

Em se tratando de Inteligência Artificial, a intervenção do Estado, aparentemente, não apresenta grandes preocupações com subsídio financeiro, já que o desenvolvimento dessas máquinas advém da iniciativa privada. De qualquer forma, é importante que o Estado desenvolva diretrizes que tragam segurança jurídica, não apenas para os fornecedores de Inteligência Artificial, mas à sociedade como um todo.

Portanto, as políticas públicas que devem ser discutidas e desenvolvidas, consistem mais no sentido de prever possibilidades de ofensa à direitos fundamentais e humanos e assegurar sua proteção por meio da transparência e fiscalização, evitando-se que dados 
pessoais sejam invadidos, que atenuem o desemprego e protejam os direitos da personalidade, com transparência e segurança.

Os avanços tecnológicos seguem com celeridade na sociedade contemporânea, que vivencia um momento digital perpetrado pela indústria 4.0. As consequências advindas desse movimento não retroagirão. Portanto, é imprescindível que haja um consenso global para traçar diretrizes éticas e jurídicas que orientem as empresas desenvolvedoras dessas tecnologias e resguardem os direitos de toda sociedade.

A união europeia já esta adotando algumas medidas e discutindo projetos de lei para este fim, assim como instituições norte-americanas e o Congresso Nacional brasileiro. Contudo, por se caracterizar uma economia globalizada, as políticas de inteligência artificial deveriam ser uniformes para evitar divergências legislativas que autorizem dispositivos inseguros ou ofensivos aos direitos humanos e de personalidade.

\section{REFERÊNCIAS}

ADORNO, Theodor W. Educação para quê? In: Educação e emancipação (pp. 139- 154). São Paulo: Paz e Terra, 2005.

ANDRADE, Mariana Dionísio de; PINTO, Eduardo Régis Girão de Castro; BARROSO, Ana Beatriz de Mendonça; LAVÔR, Amanda Rodrigues. Tecnologia e inovação: a replicabilidade do Projeto VICTOR como ferramenta de inteligência artificial do Supremo Tribunal Federal para outros sistemas. In: $6^{\circ}$ Congresso Internacional do Direito da Lusofonia, Fortaleza, 2019.

AOUN, Joseph. E. Robot-proof: higher education in the age of artificial intelligence. Cambridge, MA: MIT Press, 2017.

ARISTÓTELES. A política. São Paulo: Martin Claret, 2009.

BARFIELD, Woodrow. Liability for autonomous and artificially intelligent robots.Paladyn, Journal of Behavioral Robotics, v. 9, ed. 1, p. 193-203, 2018.

BAUERNHANSL, T.; HOMPEL, M. Ten; VOGEL-HEUSER, B. (Eds.). Industrie 4.0 in Produktion, Automatisierung und Logistik. Wiesbaden: Springer, 2014.

BAUMAN, Zygmunt. Capitalismo parasitário. Rio de Janeiro: Zahar, 2010.

BONALDO, Arianna; CUGINI, Gianvirgilio. Intelligenza artificiale: responsabilità nella progettazione e utilizzo di sistemi Analisi della tematica e riflessi legali, fiscali ed etici. In: Diritto tributario internazionale e dell'EU, Jan. p. 39- 44, 2020. 
Matheus Ribeiro de Oliveira Wolowski \& Valéria Silva Galdino Cardin

BRASIL. Conselho Nacional de Justiça. Resolução n. 332 de 21 de agosto de 2020 - Dispõe sobre a ética, a transparência e a governança na produção e no uso de Inteligência Artificial no Poder Judiciário e dá outras providências, 2020. Disponível em: https://atos.cnj.jus.br/files/original191707202008255f4563b35f8e8.pdf Acesso em: 28 ago. 2020.

BRASIL. Senado Federal. Projeto de Lei n ${ }^{\circ} 5051$, de 2019 - Estabelece princípios para o uso da Inteligência Artificial no Brasil. Senador Styvenson Valentim (PODEMOS/RN).

Disponível em: https://legis.senado.leg.br/sdleggetter/documento?dm=8009064\&ts=1582300610026\&disposition=inline Acesso em: 28 ago. 2020 .

BRASIL. Senado Federal. Projeto de Lei $n^{\circ} 5691$, de 2019 - Estabelece princípios para o uso da Inteligência Artificial no Brasil. Senador Styvenson Valentim (PODEMOS/RN).

Disponível em: https://legis.senado.leg.br/sdleggetter/documento?dm=8031122\&ts=1582300641960\&disposition=inline Acesso em: 28 ago. 2020.

BRASIL. Supremo Tribunal Federal. (ed). Inteligência artificial: Trabalho judicial de 40 minutos pode ser feito em 5 segundos. 2018. Disponível em:

http://www.stf.jus.br/portal/cms/verNoticiaDetalhe.asp?idConteudo=393522 Acesso em: 28 ago. 2020.

BRASIL. Supremo Tribunal Federal. Inteligência artificial vai agilizar a tramitação de processos no STF, 2018. Disponível em:

http://www.stf.jus.br/portal/cms/verNoticiaDetalhe.asp?idConteudo=380038 Acesso em: 28 ago. 2020.

BURRELL, J. How the machine 'thinks': Understanding opacity in machine learning algorithms Big Data \& Society, 2016. Disponível em: http://ssrn.com/abstract=2660674 . Acesso em: 01 set. 2020.

CAMPOS, L. F. A. de A.; LASTÓRIA, L. A. C. N. Semiformação e inteligência artificial no ensino. [s. l.], 2020. Disponível em:

https://search.ebscohost.com/login.aspx?direct=true \&db=edsbas\&AN=edsbas.9BC26A65\&la ng=pt-br\&site=eds-live . Acesso em: 2 set. 2020.

CONSELHO NACIONAL DE JUSTIÇA. Justiça em Números, 2019. Disponível em: https://www.cnj.jus.br/wpcontent/uploads/conteudo/arquivo/2019/08/justica_em_numeros20190919.pdf Acesso em 28 ago. 2020.

DAMILANO, C. T. Inteligência artificial e inovação tecnológica: as necessárias distinções e seus impactos nas relações de trabalho / Artificial intelligence and technological innovation: the necessary distinctions and their impacts in work relations. [s. 1.], 2019. DOI 10.34117/bjdv5n10-200. Disponível em:

https://search.ebscohost.com/login.aspx?direct=true $\& \mathrm{db}=$ edsbas \&AN=edsbas.2F1BBB0C\&la $\underline{\text { ng}}=$ pt-br\&site $=$ eds-live. Acesso em: 29 ago. 2020. 
DO CARMO, V. M.; GERMINARI, J. P.; GALINDO, F. The Advances of the Brazilian Judicial System and the Use of Artificial Intelligence: Opposite or Parallel Ways Towards the Effectiveness of Justice? Revista Jurídica (0103-3506), [s. l.], v. 4, n. 57, p. 249-283, 2019. Disponível em:

https://search.ebscohost.com/login.aspx?direct=true\&db=foh\&AN=141690435\&lang=ptbr\&site=eds-live . Acesso em: 27 ago. 2020.

EUROPEAN COMISSION. Communication Artificial Intelligence for Europe, 2018. Disponível em: https://ec.europa.eu/digital-single-market/en/news/communication-artificialintelligence-europe Acesso em: 01 set. 2020.

EUROPEAN PARLIAMENT. With recommendations to the Commission on Civil Law Rules on Robotics (2015/2103(INL). Disponível em:

https://www.europarl.europa.eu/doceo/document/A-8-2017-0005_EN.html Acesso em: 20 ago. 2020.

FLÔRES, M. L. P.; VICARI, R. M. Inteligência Artificial E O Ensino Com Computador. [s. l.], 2005. DOI 10.22456/1679-1916.13938. Disponível em:

https://search.ebscohost.com/login.aspx?direct=true\&db=edsbas\&AN=edsbas.1C484684\&lan $\mathrm{g}=\mathrm{pt}$-br\&site=eds-live. Acesso em: 2 set. 2020.

FLUSSER, Vilém. Para uma escola do futuro. Facom, 15, 4-7. 2005, Disponível em: http://www.faap.br/revista_faap/revista_facom/facom_15/_flusser.pdf Acesso em: 01 set. 2020.

HESSE, Konrad. Elementos de direito constitucional da República Federativa da Alemanha. Porto Alegre: Sérgio Antonio Fabris Editor, 1998.

KANT, Immanuel. Fundamentação da metafísica dos costumes. São Paulo: Martin Claret, 2002.

MAGALHÃES, Renato Vasconcelos. Inteligência Artificial e Direito - Uma breve introdução histórica. In: Revista Direito e Liberdade, Mossoró, v.1, n1. p.355-370, jul/dez, 2005.

MARQUES, Ana Paula Lemos Baptista. Inteligência artificial no meio ambiente de trabalho e a violação aos direitos da personalidade. Dissertação (mestrado) - UNICESUMAR - Centro Universitário de Maringá, Programa de Pós-Graduação em Ciências Jurídicas, Maringá, 95 f., 2018.

MARTIN, Nuria Belloso. Algoritmos predictivos al servicio de la justicia: ¿una nueva forma de minimizar el riesgo y la incertidumbre?. In: Revista da faculdade mineira de Direito PUC Minas. v.22. n.43,2019. p.1-31, p.10. Disponível em:

http://periodicos.pucminas.br/index.php/Direito/article/view/20780 Acesso em: 06 de set. de 2020.

PIMENTEL JÚNIOR, Gutenberg Farias. Perspectiva de personalidade para inteligências artificiais. 2013. 22f. Monografia (Conclusão de curso) - Centro de Ciências Jurídicas, 
Universidade Estadual da Paraíba, Campina Grande, 2013.

PIRES, Thatiane Cristina Fontão; SILVA, Rafael Peteffi da. A responsabilidade civil pelos atos autônomos da inteligência artificial: notas iniciais sobre a resolução do Parlamento Europeu. Revista Brasileira de Políticas Públicas, Brasília,v. 7, n. 3, p. 238-254, 2017

ROSS. Artificial Intelligence (AI) for the practice of law: An introduction. Disponível em: https://blog.rossintelligence.com/post/ai-introduction-law Acesso em: 28 ago. 2020.

RUSSELL, Stuart; NORVIG, Peter. Artificial Intelligence: A Modern Approach. 3. ed. New York City: Pearson, 2009.

SOARES, Marcelo Negri; KAUFFMAN, Marcos Eduardo; CHAO, Kuo-Ming; SAAD, Maktoba Omar. New Technologies and the Impact on Personality Rights in Brazil. In: Revista Pensar, Fortaleza, v.25, n.1, p.1-12, jan/mar, 2020. Disponível em: https://periodicos.unifor.br/rpen/article/view/9969 Acesso em: 28 ago. 2020.

SOARES, Marcelo Negri; KAUFFMAN, Marcos Eduardo; SALES, Gabriel Mendes de Catunda. Avanços da comunidade europeia no direito de propriedade intelectual e indústria 4.0: extraterritorialidade e aplicabilidade do direito comparado no Brasil. Revista do Direito, Santa Cruz do Sul, v. 1, n. 57, july 2019. ISSN 1982-9957. Disponível em:

https://online.unisc.br/seer/index.php/direito/article/view/13618 . Acesso em: 01 set. 2020.

STAATS, Sabrina Daiane. O dever de proteção aos direitos fundamentais frente a utilização de Inteligência Artificial no poder judiciário. In: Revista Brasileira de Inteligência Artificial e Direito - RBIAD, v. 1, n. 1, p. 1-18, 2020. Disponível em: https://rbiad.com.br/index.php/rbiad/article/view/3 Acesso em: 30 ago. 2020.

UNESCO. Outcome document: first version of a draft text of a recommendation on the Ethics of Artificial Intelligence, 2020. Disponível em:

https://unesdoc.unesco.org/ark:/48223/pf0000373434 Acesso em: 30 ago. 2020.

UNIÃO EUROPEIA. Regulamento (UE) 2016/679 do parlamento europeu e do conselho de 27 de abril de 2016, 2018. Disponível em:

https://www.cncs.gov.pt/content/files/regulamento_ue_2016-679__protecao_de_dados.pdf Acesso em: 30 ago. 2020.

UNI GLOBAL UNION. Top 10 principles for ethical artificial intelligence. Disponível em: http://www.thefutureworldofwork.org/media/35420/uni_ethical_ai.pdf Acesso em: 28 ago. 2020.

WHITTAKER, Meredith; et al. AI Now Report 2018. IA NOW. Disponível em : https://ainowinstitute.org/AI_Now_2018_Report.pdf Acesso em: 06 de set. de 2020. 